\title{
Raíces sociales de la violencia: el aporte del marxismo
}

El tema de la violencia encontró en la obra de Karl Marx un tratamiento expreso; también la tradición marxista posterior hizo énfasis sobre algunos de los tópicos tratados por Marx. El tratamiento que hace este autor del tema de la violencia se inscribe en el marco de su teoría de la alienación, cuya elaboración comenzó en los Manuscritos económico-filosóficos de 1844 y culminó en El Capital, su obra cumbre'.

En estas notas haremos una evaluación somera de las tesis sobre la violencia presentes en el pensarniento marxista. El propósito de la misma es aportar a la discusiones actuales sobre la violencia elementos conceptuales que permitan comprender el carácter social de la violencia. Obviamente, la perspectiva marxista no agota todos los aspectos que se pueden discutir sobre aquélla; sin embargo, deja apuntados algunos que son insoslayables y que, además, pueden dar pie para ulteriores indagaciones sobre las raíces sociales de la violencia.

\section{Teoría de la alienación ${ }^{2}$}

En sus componentes esenciales, esta teoría se puede resumir como sigue: en el capitalismo, la burguesía, en virtud de la apropiación privada de los medios fundamentales de producción, se apropia de los bienes generados en el proceso productivo". Estos se presentan ante quienes los producen - los trabajadorescomo entidades ajenas, con una realidad propia a la que ellos deben de someterse.

Al decir de Manx: "si el producto del trabajo no pertenece al trabajador, si es frente a él un poder extraño, esto sólo es posible porque pertenece a otro hombre, que no es el trabajador... mediante el trabajo enajenado crea el trabajador

- Maestro en Ciencias Sociales por la FLACSO-México. Director del Centro de Información, Documentación y Apoyo a la Investigación (CIDAI) de la UCA. 
una relación de este trabajo con un hombre que está fuera del trabajo y le es extraño... Partiendo de la Economía Política hemos llegado ciertamente al concepto de trabajo enajenado (...) como resultado del movimiento de la propiedad privada"4.

A partir de este principio generador de la enajenación económica (la alienación fundamental), se derivan otras dinámicas de alienación como la jurídicopolítica (el Estado se autonomiza ${ }^{3}$ y la ideológica (las ideas cobran vida propia $^{6}$ ). Bajo el capitalismo, el conjunto de estas alienaciones permea la vida de los individuos, dando lugar a una fetichización de las relaciones que éstos establecen entre sí.

En un texto ya clásico, Marx dejó escrito lo siguiente respecto del fetichismo: "si queremos encontrar una analogía a este fenómeno tenemos que remontamos a las regiones nebulosas del mundo de la religión, donde los productos de la mente humana semejan seres dotados de vida propia, de existencia independiente, y relacionados entre sí y con los hombres. Así acontece con el mundo de las mercancías, con los productos de la mano del hombre. A esto es a lo que yo llamo el fetichismo bajo el que se presentan los productos del trabajo tan pronto como se crean en forma de mercancias" ${ }^{17}$.

En Marx, pues, los individuos, bajo el capitalismo, no son dueños de sus creaciones, sean estas económicas, jurídico-políticas o ideológicas; las mismas se les presentan en su vida práctica como entidades ajenas y dotadas de una lógica propia, externa a sus creadores. El mundo de las cosas termina imponiendo su ritmo al mundo humano, lo cual da lugar a una cosificación de las relaciones sociales, es decir, a que las relaciones sociales entre las personas no se presenten como tales en la conciencia de los actores, sino como "relaciones materiales entre personas y relaciones sociales entre cosas"'

En su origen, esa cosificación tiene por base la apropiación privada de los medios de producción por parte de una clase, la burguesía, la cual se sirve del aparato estatal y de la ideología —en el entendido de que la ideología dominante es la ideología de la clase económicamente dominante- para perpetuar su dominio económico.

En este sentido, la política y la ideología no sólo son ajenas a los individuos, sino que, en parte, esa enajenación es funcional a los intereses de la clase dominante: la ideología sirve de "ilusión" que hace creer que los cambios reales son resultado del cambio en las ideas; el Estado, como concreción privilegiada de la política, se presenta como garante formal del bien común y del interés generah, cuando en realidad protege activamente los intereses de los propietarios de los medios de producción.

¿Qué hacer ante un mundo cosificado? Para Marx, la respuesta es clara: hay que subvertir revolucionariamente el orden social establecido, fundando un nue- 
vo orden, en el cual la propiedad privada de los medios de producción - fuente última de la alienación - sea abolida y reemplazada por la apropiación social de los mismos. Esa ingente tarea corre por cuenta de la clase que, de todas las existentes, tiene todo que ganar (la redención total) y nada que perder (pues se ha perdido incluso a sí misma) en el proceso: la clase proletaria.

Eliminada la propiedad privada - piensa oplimistamente Marx-, será factible encaminarse a la abolición de las alienaciones que de ella se derivan y, más aún, de la cosificación imperante en la sociedad capilalista en su conjunto. Pero, para eliminar la alienación económica, habrá que comenzar por dar la batalla a las alienaciones ideológica y política, pues es de ésta de donde saldrán los instrumentos para arribar a aquélla.

Una vez que la clase proletaria, organizada como es debido, se inserte en la dinámica apuntada, el desenlace previsto —el fin de toda alienación y cosificación- estará asegurado. Se arribará al comunismo o "reino de la libertad", esto es, ese orden social en el cual "la libre individualidad [estará] fundada en el desarrollo universal de los individuos y en la subordinación de su productividad comunitaria (...), social, como patrimonio social [la cual estará] subordinada a los individuos y controlada comunitariamente (...) por ellos como un patrimonio"y. Se instauraría, así, una sociedad plenamente humanizada, una sociedad en la que llegará a su fin el trabajo impuesto por la necesidad externa".

Muy apretadamente hemos resumido las tesis básicas de la teoría de la alienación de Karl Marx. Como veremos a continuación, sus reflexiones sobre la violencia se inscriben en el interior de sus planteamientos sobre la alienación, porque en definitiva ésta, en sus diversas manifestaciones, expresa una situación de violencia que no puede ser soslayada.

\section{Alienación y violencia}

En forma muy esquemálica podemos resumir el problema de la violencia en la sociedad capitalista, según el planteamiento de Marx, a partir de los siguientes elementos: (a) la alienación económica supone la separación, por la violencia, entre los trabajadores y las condiciones de producción; $(b)$ el aparato jurídico-político (cristalizado en el Estado) tiene como funciones fundamentales controlar coercitivamente los posibles desbordes de las clases subordinadas o reprimirlos violentamente si se hacen efectivos; (c) las clases subordinadas pueden revertir la situación de despojo económico (alienación económica), para lo cual tienen que valerse de la violencia en dos sentidos: para desplazar del control del Estado a la clase dominante y para, desde el poder de estado recién conquistado, dar inicio a la recuperación por parte de los trabajadores de sus condiciones de producción; y (d) toda forma de violencia llagará a su fin una vez que los vestigios de las formas de dominación económica del viejo orden (el orden burguess) sean erradicados totalmente, es decir, cuando se instaure la sociedad comunista. 
El conjunto de esos aspectos resume el planteamiento de Marx sobre la violencia. Detengámonos someramente en cada uno de ellos.

(a)La alienación económica da pie a lo que en discusiones sociológicas posteriores se dio en llamar violencia estructural. Se trata de un tipo de violencia que hunde sus raíces en la estructura económica de la sociedad y que consiste, como señalamos antes, en el despojo que padecen los trabajadores de sus condiciones de producción. Este despojo se inserta, para Marx, en el proceso a partir del cual se constituye la sociedad capitalista: la acumulación originaria de capital. En efecto, en su desanrollo, el trabajador directo es separado mediante la fuerza (estatal y privada) de sus condiciones de trabajo y reproducción, especialmente la tierra. Y ello porque esa separación es el supuesto necesario para el surgimiento de una mano de obra libre, es decir, dispuesta a venderse a cambio del salario ofrecido por los empleadores capilalistas.

Los trabajadores, pues, son alienados de sus condiciones de trabajo. Ello sucede a través del uso de la fuerza, cuyos niveles pueden ser tan elevados como elevada sea la resistencia de aquéllos. Además, esta violencia estruclural no se agota en el proceso en el que nace la sociedad capitalista, sino que se mantiene como requisito suyo a medida que ésta se expande y consolida. Esto sucede porque la clase privada de sus condiciones de producción - la clase trabajadora- vive permanentemente padeciendo las consecuencias del despojo del que fue objeto, lo cual se expresa en su condición de pobreza y marginalidad socioeconómica. Es decir, el despojo de sus condiciones de producción condena a la clase proletaria, mientras esa separación no sea erradicada, a la pobreza y la deshumanización más absolutas" ${ }^{\prime \prime}$ No otra realidad expresa, en la tradición de pensamiento marxista, el término violencia estructural.

(b) Los trabajadores fueron separados de sus condiciones de trabajo principalmente por la fuerza del Estado, esto es, por la utilización de determinados mecanismos de coerción estatales, entre los cuales los mas relevantes son la policía y los tribunales. Una vez operada la separación señalada, la policía y los tribunales ejercen su rol de vigilanles del orden establecido, asumiendo un papel abiertamente represivo toda vez que las clases subaltemas lo perturben ya sea instintiva o conscientemente. En este sentido, la función del Estado consiste en ser instrumento de dominio de la clase burguesa sobre las demás clases, en el entendido de que el Estado es tanto una "máquina para mantener el domino de una clase sobre olra"12 como "la forma bajo la que los individuos de una clase dominante hacen valer sus intereses comunes y en la que se condensa loda la sociedad civil de una época"13.

Del Estado emerge una violencia poltica, que se ejerce sobre todos aquellos, incluidos miembros de la misma burguesía, que perturban el orden establecido. Esa perturbación puede obedecer a resentimientos de clase, a una resistencia instintiva a la dominación - la cual se puede manifestar en diferentes hechos de 
violación a la legalidad- o a un movimiento consciente del proletariado en busca de derribar al poder burgués. Es en este último caso cuando la violencia política se vuelve totalmente explícita, pues los aparatos de coerción del Estado -y en muchas ocasiones las milicias privadas de los sectores dominantesponen en práctica medidas de fuerza legales e ilegales (dentro de éstas es usual el terrorismo de Estado) para contener el ascenso del proletariado.

(c) A la violencia estatal, la clase proletaria no tiene más remedio que responder - una vez que ha cobrado conciencia de la situación - con una dosis igual o superior de violencia. Se trata de una violencia revolucionaria, puesto que su sentido último estriba en traslocar radicalmente el orden burgués establecido, reemplazándolo por un orden distinto. Si el Estado es el aparato de dominio de la burguesía, una tarea prioritaria es enfrentarlo, para lo cual es necesario contar con una organización -el partido comunista- capaz de orientar la lucha proletaria contra el Estado de la burguesía.

Así pues, a la violencia organizada de la clase dominante, el proletariado tiene que oponer la violencia organizada de su clase ${ }^{14}$, la cual atraviesa por dos fases: la primera, aquélla en la que, generalmente pasando por una guerra civil, la organización proletaria desarticula los organismos represivos del Estado (ejército, policía, tribunales); la segunda, aquélla en la que el proletariado utiliza el aparato estatal para destruir los resabios burgueses (en la economía, la sociedad y la política) y crear las condiciones para la configuración de una sociedad sin Estado y sin clases's.

(e) Entre el fin de la sociedad capitalista y la sociedad futura, comunista, se interpondrá una situación intermedia de "transición", conocida como la "dictadura revolucionaria del proletariado"16. En esta etapa se ejercerá la violencia política, cuyo objetivo preciso será erradicar los vestigios del antiguo régimen. A la misma le será intrínseca la transitoriedad, es decir, el estar diseñada para llegar a su fin una vez que su objetivo haya sido cumplido. Llegado este momento, no sólo desaparecerá la violencia política, sino todas las formas de violencia existentes.

La violencia política del proletariado, una vez instalada su dictadura, será una violencia usada para erradicar las violencias fundamentales en el capitalismo: la violencia política, pues no existirán las clases; la violencia económica, pues habrá desaparecido la alienación económica al recuperar los trabajadores sus condiciones de producción. En palabras de V.I. Lenin: "nosotros proponemos como meta final la abolición del Estado, es decir, de toda violencia sistemática y organizada, contra todo el uso de la violencia contra el hombre en general... Pero, aspirando al socialismo, estamos persuadidos de que se convertirá gradualmente en comunismo y en relación con esto desaparecerá toda necesidad de violencia sobre los hombres en general, toda necesidad de subordinación de unos hombres a otros, y de una parte de la poblacion a otra, pues los hombres se 
habituaran a observar las reglas elementales de la convivencia social sin violencia y sin subordinación"17.

Como podemos ver, el tratamiento del tema de la violencia en la tradición marxista pone de relieve su dimensión instrumental. En primer lugar, la violencia que se ejerce en el despojo de la acumulación originaria tiene como objetivo separar a los trabajadores de sus condiciones de producción; la que se ejerce desde el Estado tiene como propósito ya sea controlar posibles brotes de resistencia antisistema o reprimirla cuando se hace efectiva. En ambas situaciones, además, se utilizan mecanismos diseñados ex profeso para ejercer la violencia: los cuerpos armados y los tribunales. Estos, además, suelen racionalizar el ejercicio de la violencia, es decir, buscan no sólo minimizar sus costos de funcionamiento, sino maximizar su efecto coercitivo.

En segundo lugar, la violencia liene una dimensión instrumental también para el proletariado, quien la ejerce, primero, para hacer frente al Estado burgués y, después, para poner en marcha el proceso de socialización de las condiciones de producción. Sin una dosis de violencia a las clases subordinadas les sería imposible desencadenar y llevar a feliz término el proceso de emancipación definitiva de la humanidad; es por ese fin que se legitima y justifica la violencia revolucionaria organizada.

En tercer lugar, el planteamiento marxista hace énfasis en la violencia como algo externo a los individuos. Sea como coerción-represión estatal, enajenación económica o lucha revolucionaria, la violencia es algo que se ejerce desde fuera sobre los individuos que la padecen y algo que éstos ejercen sobre quienes iniciaron el ciclo de violencia para defenderse y revertir la situación. Se trata, entonces, de una externalidad a los individuos; de algo que viene de fuera y que hay que combatir hacia afuera. Y lo que haya de violencia en el interior de la persona humana, al igual que otros componentes de su personalidad, tiene un origen exógeno. Por algo Marx llegó a asentar, con particular fuerza, en sus Tesis sobre Feuerbach (Tesis VI) que la esencia humana "es, en su realidad, el conjunto de las relaciones sociales".

En cuarto lugar, cabe destacar el optimismo marxista ${ }^{18}$ acerca del fin de la violencia. Este optimismo tiene su razón de ser, primero, en el historicismo de Marx y, segundo, en su visión de la violencia como un fenómeno eminentemente social. En el esquema de Marx, la historicidad no sólo hace transitorios los diversos fenómenos humanos, sino también los inscribe en un proceso de humanización de largo aliento que condena a su desaparición a todo aquello que empaña la vida humana en el presente. Por olra parte, como fenómeno social, la violencia es una realidad objetiva exterior a los individuos, una realidad que éstos pueden domeñar, una vez conocidas sus fuentes y mecanismos, aplicando medidas de la más diversa naturaleza, entre las que no se excluye la utilización de la fuerza. 
Finalmente, en el esquema marxista está presente una concepción terapéutica para hacer frente a la violencia. Mientras perdure la violencia estructural, las clases subalternas se van a revelar de diversas formas contra las clases dominantes; éstas, por consiguiente, van a tener que diseñar múltiples mecanismos para controlar (sin poder extirparlos nunca y de raíz) esos brotes de malestar social' ${ }^{19}$. Las clases dominadas, mientras no llegue la hora final de la violencia (el comunismo), van a tener que implementar diversas medidas - como la organización sindical, el cooperativismo, etc.- encaminadas a hacer menos lacerantes las condiciones de explotación capitalistas. Pero sólo se tratará de medidas paliativas, puesto que las violencias estructural y política seguirán imponiéndose sobre ellos mientras perdure el sistema.

\section{Reflexión crítica}

Si aceptamos que el esfuerzo teórico de Marx estaba dominado por un afán científico, debemos estar dispuestos a aceptar, también, a más de cien años de su muerte, la necesidad de revisar su legado sociológico, económico, histórico y político. Esta valoración debe estar encaminada a discernir sobre cuáles son aquellos aportes de Marx que aún tienen potencia explicativa de la realidad social y cuáles la han perdido o, al menos, deben ser reexaminados a la luz de los aportes de las ciencias sociales conlemporáneas.

En lo que respecta al problema de la violencia, el aporte teórico de Marx es, en algunos de sus aspectos, de gran relevancia analítica. En primer lugar, su concepción de lo que es la violencia estructural, su origen y sus mecanismos perversos de funcionamiento, es un aporte de gran valor para el análisis de las sociedades latinoamericanas y africanas contemporáneas. Las distintas aproximaciones conceptuales al problema de la marginación socioeconómica que se hacen en la actualidad, cuya pretensión científica es inobjetable, se remiten a las tesis de Marx sobre el tema de la violencia estructural.

En segundo lugar, como pocos autores, Marx supo desentrañar el sentido y. los mecanismos de la violencia polttica, cuya relevancia en la dinámica de las sociedades capitalistas, desde los tiempos de Marx hasta bien entrado el siglo XX, es innegable. En América Latina, desde finales del siglo XIX hasta finales de los años ochenta, este tipo de violencia, tanto en su carácter estatal y paramilitar como en su carácter contestatario y popular, fue el eje central de la dinámica política. Incluso, en buena medida por el influjo del planteamiento marxisla, se llegó a formular la idea de la "espiral de la violencia", idea que hacía alusión a la secuencia siguiente: violencia estructural (originaria) $\rightarrow$ violencia de resistencia instintiva (popular) $\rightarrow$ violencia institucional (estatal) $\rightarrow$ violencia organizada (popular) $\longrightarrow$ represión estatal generalizado y terrorismo de Estado. Era casi imposible lograr una comprensión medianamente clara de la realidad social latinoamericana - marcada por regímenes políticos autoritarios, econo- 
mías excluyentes de la mayor parte de la población y movimientos sociales radicales - sin tomar en cuenta la lógica de la violencia que la regía.

En tercer lugar, en el tratamiento marxista de la violencia cobra relevancia su dimensión instrumental ${ }^{20}$. La violencia sirve para lograr determinados propósitos, ya sean estos económicos o políticos; es decir, sirve de medio para alcanzar determinados fines. No es irrelevante para las ciencias sociales el que Marx haya puesto de relieve esta dimensión de la violencia y, más aún, que haya logrado establecer delerminados tipos de violencia que se caracterizan por su instrumentalidad. Esta perspectiva analítica es un herramienta de valor en los estudios contemporáneos sobre violencja, los cuales han permitido identificar muchos más tipos de violencia instrumental —que se circunscriben en su gran mayoría al ámbito individual-que los contemplados por Marx.

En cuarto lugar, Marx puso de relieve el carácter objetivo de la violencia. En virlud de ello, la violencia —su erradicación total- no es algo que pueda estar sujeto a la mera voluntad humana, puesto que tiene una realidad allende a ésta: en la base económica y la superestructura jurídico-política. En el capitalismo, nos enseñó Marx, los individuos tienen que convivir, hasta que no se arribe al comunismo, con la violencia y sus mecanismos de funcionamiento. Tienen que vivir con la violencia que ejercen las clases dominantes, a través de la economía y la política, y la violencia que ejercen las clases subalternas para resistir la violencia de las primeras y preparar el advenimiento de una sociedad sin violencia.

Por último, junto con la idea de la objelividad de la violencia, Marx pone de relieve lo inexorable que es para los hombres vivir con ella, al menos mientras existan las sociedades divididas en clases. Si no nos dejamos arrastrar por el optimismo de Marx y asumimos que la sociedad idilica que él nos propone difícilmente será alcanzada en algún momento en la historia de la humanidad, entonces llegamos a la conclusión de la que la violencia nunca será erradicada de la convivencia social. Es decir, que los seres humanos tendrán que aprender a vivir, ahora como en el pasado, con la violencia no como algo accidental, sino como algo inscrito en la estruclura social. Si se suprime de Marx el elemento ulópico, su planteamiento sobre la violencia viene a ser coherente con otras teorías sociales, para las cuales aquélla es un componente ineludible e inextirpable de la vida social del hombre.

En fin, los aspectos anteriormente señalados son parte del legado teórico del marxismo para la comprensión del fenómeno de la violencia. Se trata, por lo demás, de un aporte parcial, en cuanto que el mismo deja de lado dimensiones de aquélla que fueron exploradas por otras tradiciones intelectuales. La pregunta que se impone es la siguiente: ¿qué es lo que quedó fuera de la consideración que Marx hizo sobre la violencia? Para responderla, vamos a señalar algunos de los déficit o puntos débiles del análisis marxista de la violencia. 
En primer lugar, la confianza excesiva de Marx en la violencia (revolucionaria) para terminar con todo tipo de violencia. La experiencia histórica mostró, con las llamadas dictaduras del proletariado que se establecieron en el ex bloque del Este y la ex URSS, que los regímenes políticos que nacieron al calor de ellas llegaron para quedarse en el poder por un tiempo indefinido; tiempo durante el cual se ejercieron los más diversos tipos de violencia estatal que en lo absoluto estaban encaminados a erradicar la violencia, sino a generar focos de resistencia antitotalitaria que terminaron dando al traste con los "socialismos reales". Tal vez Marx no se equivocó al señalar que una violencia (estructural y política) genera otra violencia encaminada a resistirla y doblegarla; sí se equivocó quizás al creer que quienes doblegaban a los violentos utilizando la violencia iban a renunciar al monopolio de la misma.

En segundo lugar, el excesivo peso que tiene en Marx lo macro. Las categorías principales de su concepción -alienación económica, Estado, proletariado, violencia de clases, etc.- son de índole colectiva y macrosocial. La violencia es un fenómeno económico, social y político, y sólo derivadamente un fenómeno individual. No es que, como recordó en su momento Adam Schaff, los individuos estén ausentes en la concepción de Marx, pero su vida individual es la resultante de las relaciones sociales (políticas, económicas y culturales) que cristalizan en ella. En consecuencia, las fuentes de la configuración de la personalidad humana están en la sociedad. Se entiende por qué, en el tratamiento que hace Marx de la violencia, no sólo quede excluido el individuo, sino que, además, se pongan de relieve sus características macrosociales y macropolíticas: la misma tiene como sujelos privilegiados a colectivos de los cuales es parte subordinada el individuo.

Esta perspectiva, en tercer lugar, impidió a Marx y a una buena parte de la tradición marxista posterior -la que siguió las sendas del marxismo-leninismo- examinar no sólo los microfundamentos de la violencia, sino manifestaciones de la misma muy puntuales y difíciles de insertar en el marco contemplado por la violencia estructural y la violencia política. El examen de los microfundamentos ${ }^{21}$ hizo volver la vista hacia los individuos, concebidos ya no como marionetas de la sociedad o como una cristalización de las relaciones sociales, sino como siendo en parte eso y en parte algo distinto: una realidad que, además de anclar sus raíces en la sociedad, tiene una filiación biológica (animal) ineludible, a cuya sombra se fraguan las más complejas conductas humanas y cuya lógica es difícil desentrañar.

Finalmente, el examen de diversas manifestaciones de violencia, más específicas que las contempladas en las relaciones de clase, revela que en muchas de ellas era casi imposible establecer el componente económico y político que las adscribiera a los marcos conceptuales de procedencia manxista. Asimismo, una gran gama de tipos de violencia se circunscriben a círculos de relaciones 
microsociales, en los cuales la acción-interacción individual cobra una preponderancia inocultable. Además, en ese ámbito microsocial a veces es relativamente fácil caracterizar un acto violento como instrumental, pero a veces ello se vuelve totalmente imposible, pues no aparece por ninguna parte la relación medio-fin propia de la lógica instrumental.

Estas limitaciones han dado la pauta para revisar el corpus teórico marxista, con el objetivo de reconsiderar algunos de sus supuestos básicos y dotarlo de nuevas herramientas analíticas (como lo hace, por ejemplo, el manxismo analíti$\mathrm{co}^{22}$ ), o buscar su confluencia con otros cuerpos teóricos (por ejemplo, el psicoanálisis), con el propósito de recuperar dimensiones de la realidad humana (la instintiva-emocional) tratada insuficientemente por la tradición marxista. Queda para futuros trabajos la dilucidación de estas revisiones.

San Salvador, 1 de agosto de 1998.

\section{Notas}

1. Para un balance de la teoría de la alienación en Marx, ver González, Luis Armando y Sermeño, Angel, El estatuto práxico de la teoría de la alienación de Marx, Tesis de Licenciatura en Filosofía, UCA, San Salvador, 1988.

2. Podría parecer anacrónico volver a la teoría de la alienación de Marx; sin embargo, una respetable variante del marxismo actual —el marxismo analítico- considera que la misma es uno de los legados de Marx que aún tiene vigencia. Ver Elster, J., Una introducción a Karl Marx, México: Siglo XXI, 1991.

3. Para una visión de conjunto del pensamiento económico marxista, ver Kühne, Karl, Economía y marxismo, México: Grijallbo, 1979.

4. Marx, Karl, Manuscritos: economía y filosofia, Madrid: Alianza, 1970, pp. 114-116.

5. Ver Marx, Karl, La ideología alemana, La Habana: Pueblo y educación, 1982, pp. 33-34.

6. Ibid., pp. 48-49.

7. Marx, Karl, El Capisal, México: FCE, 1972, p. 37.

8. Ibid., p. 38.

9. Marx, Karl, Elementos fundamentales para la crítica de la economía politica (Grundrisse), México: Siglo XXI, Vol. 1, 1986, p. 85.

10. Ver González, Luis Armando, "El concepto de praxis en Marx: la unidad de ética y ciencia", Realidad económico-social, No. 19-2, enero-abril, 1991, pp. 195-226.

11. Sobre la degradación del obrero en el capitalismo, ver Marx, Karl, "Salario, precio y ganancia", en Obras escogidas, Moscú: Progreso, p. 225 y ss. El lumpenproletariado, integrado por los mendigos, ladrones, trabajadores itinerantes, cómicos, burgueses proscritos, tahúres, libertinos y prostitutas, es también un subproducto de la miseria humana generada por el capitalis- 
mo. Ver Collins, Randall, Cuatro tradiciones sociológicas, México: UAM, 1996, p. 69.

12. Lenin, V.I., "Acerca del Estado", en Obras escogidas, Vol. Ill, Moscú, p. 265.

13. Marx, Karl, La ideologia... p. 69. Entre la amplia bibliografía existente sobre el tema, otras ideas interesantes sobre el problema del Estado en Marx se pueden encontrar en Nicos Poulantzas, Poder politico y clases sociales en el Estado capitalista, México: Siglo XXI, 1973; también en De Geovanni, Biagio, "Marx y el Estado", en AAVV Teoría marxista de la politica, México: Pasado y presente, 1981, pp. 28-68.

14. Para Marx se trata de una violencia organizada y consciente, es decir, fundada en el conocimiento científico de la realidad. Aquí es oportuno citar a G. Sorel, quien fue uno de los intelectuales que insistió, en sus Reflexiones sobre la violencia (1905), en las fuentes imacionales (míticas) de la violencia revolucionaria.

15. Para una valoración crítica de la teoría del conflicto político en Marx, ver Collins, Randall, op. cit., pp. 75-83.

16. Marx, Karl, "Crítica al programa de Gotha", en Obras escogidas, Moscú: Progreso, p. 342.

17. Lenin, V.I., El Estado y la revolución, Moscú: Progreso, 1976, p. 78.

18. Marx logra articular de una forma discutible su visión estructural de la realidad social con su optimismo emancipatorio. La Escuela de Frankfurt, sobre todo de la mano de Habermas, ha intentado mantener la tensión entre ambos aspectos. Desde la teoría de sistemas de Lhumann, en muchos aspectos coincidente con la teoría social habermasiana, se hecha por la borda ese optimismo, puesto que el sistema, con sus subsistemas coercitivos, no sólo se impone omnímodo sobre los individuos, sino que carnina hacia donde sus necesidades de reproducción se lo exigen, siendo los propósitos de emancipación sólo una vana ilusión. Ver González, Luis Armando, "Teoría crítica versus teoría de sistemas", Realidad, No. 41, septiembre-octubre, 1997, pp. 785-812.

19. Esta visión fue llevada incluso hasta la psiquiatría por autores italianos que vieron en ella "un instrumento de represión y de control de las posturas desviantes... [ una práctica que] pone las bases para una estrecha colaboración entre psiquiatría, jueces y policía". Jervis, G., Psiquiatría y sociedad Caracas: Fundamentos, 1981, p. 39. También se puede consultar Basaglia, Franco, et. al., Los crímenes de la paz, México: Siglo XXI, 1981.

20. La violencia instrumental puede entenderse como parte del imperio que la racionalidad instrumental ejerce sobre la sociedad capitalista. Ver Heorkeimer, Max y Adomo, T.W., Dialéctica de la llustración, 1946; González, L.A., "Neoconservadores, postmodemos y teóricos críticos", Merapolítica, México, No. 1, enero-marzo, 1997, pp. 72-81. 
21 Por cierto, el giro hacia los microfundamentos ha sido asumido por una corriente del marxismo —el marxismo analítico- ahora en auge. Ver Roemer, J.E. (Comp), El marxismo: una perspectiva analítica, México: FCE, 1989.

22 Ver Gonzalez, L.A., "Marxismo analítico: ¿una altemativa a la crisis teórica del marxismo?, Realidad, No. 49, enero-febrero, 1996, pp. 135-152. 